\title{
A GIS-Based Effort to Identify a Potential Movement Corridor for Western Purple- Faced Langur (Semnophithecus vetulusnestor), between Labugama-Kalatuwawa and Indikada Forest Reserves in Colombo District of Sri Lanka
}

\author{
Panagoda P.A.B.G.*, Weerasinghe V.P.A. \\ Department of Zoology \& Environmental Management, University of Kelaniya, Sri Lanka \\ *gayomini1@gmail.com
}

\begin{abstract}
The contribution of Labugama-Kalatuwawa Forest Reserve (LKFR) and Indikada Forest Reserve (IFR) in Colombo District of Sri Lanka, for maintaining viable populations of Western purple-faced langur (Semnophithecus vetulus nestor), have long been recognised. In between these two forests, a mosaic of unprotected land uses i.e., home gardens, rubber (Hevea brasiliensis) and rambutan (Nephelium lappaceum) monoculture, Seetawaka wet zone Botanical Garden and forest patches are scattered, isolating the two protected areas from each other. As the safe traversing of langurs between these two forests is not ensured at present, this study aimed to identify a potential linkage through developing a movement corridor for $S$. $v$. nestor between LKFR and IFR. The study was conducted in a $5.36 \mathrm{~km}^{2}$ strip of an unprotected landscape, located between LKFR and IFR which includes another small forest which is called Gatemawara Forest Reserve (GFR). The area was divided into 4ha grids and data were collected to prepare the five input layers: land-use type, road density, \% canopy cover, human tolerance and feeding plant species richness and density (FPSD). It was assumed that the occurrence and abundance of $S$. v. nestor at a particular location, directly depends on the aforementioned factors. Using weighted overlay functions of ArcGIS 10.2.2, the layers were overlaid and an analysis of least-cost path was carried out to identify the best potential corridor. The resultant corridor passes mainly through forest and rubber land-uses, especially including GFR. In addition, the corridor grids account for the highest tolerance of langurs, canopy continuity and FPSD and least road density, all supporting to a successful transit. However, the corridor passes through Puwakpitiya-Thummodara main road, bisecting the landscape between LKFR and IFR which acts as a permanent barrier for langur movement. Still, this can be off-set by establishing proper crossing structures such as rope bridges. The current assessment indicates that there is considerable habitat connectivity for $S$. $v$. nestor, between LKFR and IFR. Further habitat enrichment across the corridor is recommended, which might allow S. v. nestor to be selective of those grids. In conclusion, when the existing gaps are bridged and the corridor habitats are enriched, the identified corridor would play an important role in conservation of $S$. v. nestor, minimizing the isolation of local populations, ensuring the gene flow and maintaining the minimum viable metapopulation in the long run.
\end{abstract}

Keywords: Wildlife corridors, Western purple-faced langur, Least-cost path analysis, Labugama-Kalatuwawa forest reserve, Indikada forest reserve

Proceedings of the $22^{\text {nd }}$ International Forestry and Environment Symposium 2017 of the Department of Forestry and Environmental Science, University of Sri Jayewardenepura, Sri Lanka 